\title{
The methodology for X-ray diffraction investigation of icosahedral quasicrystals substructure
}

\author{
S.V.Bazdyreva, N.V.Fedchuk, S.V.Malykhin, \\ A.T.Pugachov, M.V.Reshetnyak, E.N.Zubarev \\ National Technical University "Kharkiv Polytechnical Institute", \\ 21 Frunze Str., 61002 Kharkiv, Ukraine
}

Received August 11, 2012

\begin{abstract}
Method of quantitative estimates of the parameters of the icosahedral quasicrystals substructure, including specific phason defects, developed and successfully worked out using the experimental models of quasicrystalline $\mathrm{Al}_{70} \mathrm{Pd}_{21} \mathrm{Re}_{9}, \mathrm{Ti}_{41.5} \mathrm{Zr}_{41.5} \mathrm{Ni}_{17}$ and $\mathrm{Al}_{64.5} \mathrm{Pd}_{21} \mathrm{Mn}_{14.5}$ with different preparation technology. The method is based on the analysis of the diffraction lines' width of complete X-ray diffraction pattern. The results are in a good agreement with the prehistory of the samples.
\end{abstract}

$\mathrm{C}$ использованием опытных квазикристаллических образцов $\mathrm{Al}_{70} \mathrm{Pd}_{21} \mathrm{Re}_{9}$, $\mathrm{Ti}_{41,5} \mathrm{Zr}_{41,5} \mathrm{Ni}_{17}$ и $\mathrm{Al}_{64,5} \mathrm{Pd}_{21} \mathrm{Mn}_{14,5}$ с различной технологией приготовления разработана и успешно апробирована методика количественной оценки параметров субструктуры в икосаэдрических квазикристаллах, включая специфические фазонные дефекты. В основу метода положен анализ ширины дифракционных линий полной картины рентгеновской дифракции. Полученные результаты находятся в хорошем согласии с предисторией образцов.

\section{Introduction}

The structure of icosahedral quasicrystals (QCs) discovered by D.Shechtman in 1984 [1] is characterized by aperiodic (quasiperiodic) long-range order, an absence of any translation and rotational symmetry forbidden for the crystals $[2,3]$. An unusual atomic structure of QCs defines a number of new combinations of physical and chemical properties $[3,4]$. To characterize the properties being dependent on the structure, it is important to understand their subjection to the type and distribution of structural defects. It is known that the concept of QCs substructure along with the density and distribution of dislocations (as well as for crystals), includes also phason defects. The last ones are specific defects peculiar to the icosahedral structure [5]. The unique interpretation of the "phason defect" concept does not exist in the literature today, that can be observed from the broadened discussions [6]. The concept of "phason," "phason jumps", "phason strain" and "phason modes" are being discussed [7-12]. In the model of icosahedral quasicrystal structures composed of regularly arranged two types of rhombohedrons in an irrational ratio, "phason" appears as a consequence of the rhombohedrons stowage rules violations, and can be considered as a kind of point defects. A single "phason jump" is an error in the stowage of rhombs tiles in case of two-dimensional Penrose tilling [13]. Such defect adds some local topological and chemical disorder into the structure. It creates a strain field around itself, and upsets the phase of the scattered wave [2]. On the diffraction patterns from single grains QCs the presence of phasons becomes apparent in decreasing of intensity, broadening and 
shifting appropriate reflections and appearance of the maxima of the diffuse scattering. It was established [14] that these effects are stronger while the higher is the component value of the diffraction vector in the perpendicular subspace $-\mathbf{Q}_{\perp}$. Sometimes there is the anisotropy of changes of the diffuse maxima width [9, 15]. Proceeding from the aforesaid, the presence of phason defects in the structure is qualitatively assessed by the change of the position and width of the diffraction peaks [14,15, $17,18]$. Attempts for quantitative estimating of the phason defects concentration have a single character and give conflicting results [12, 14, 19].

Therefore the aim of this study was to develop an X-ray method for study of icosahedral quasicrystals, parameters of the substructure and quantitative assessment of average value of microdeformations, size of the domains of coherent scattering (DCS) and density of the phason defects.

\section{Samples and methods of research}

For studying the samples were taken, which contained $100 \%$ of the icosahedral phase according to the previous studies [2022]. Technologies of the samples preparation were different, that suggests a priory different density and distribution of defects in the samples. Some quasicrystalline samples were ribbons of $\mathrm{Ti}_{41.5} \mathrm{Zr}_{41.5} \mathrm{Ni}_{17}$ and $\mathrm{Al}_{64.5} \mathrm{Pd}_{21} \mathrm{Mn}_{14.5}$ with $20 . .50 \mu \mathrm{m}$ thick obtained by superfast quenching of the melt. Massive $\mathrm{Al}_{70} \mathrm{Pd}_{21} \mathrm{Re}_{9}$ sample was obtained by solidification in normal conditions. Another fine-dispersed $\mathrm{Ti}_{41.5} \mathrm{Zr}_{41.5} \mathrm{Ni}_{17}$ sample was prepared by an intensive fragmentation of ribbons in an agate mortar. At the samples selection we based on the established opinion that phasons in the structure can be introduced during the quenching or deformation [4]. To analyze this structure the method of X-ray diffraction and transmission electron microscopy was used. For processing of diffraction patterns and determining the parameters of the diffraction peaks the software package New Profile 3.5 was used.

X-ray study of a substructure is usually carried out by methods of harmonic analysis or approximation on the diffraction peaks width of multiple order reflections using the sample standard to eliminate a geometric broadening. Since the harmonic analysis requires diffraction lines of the standard and sample to be placed on the same corner,

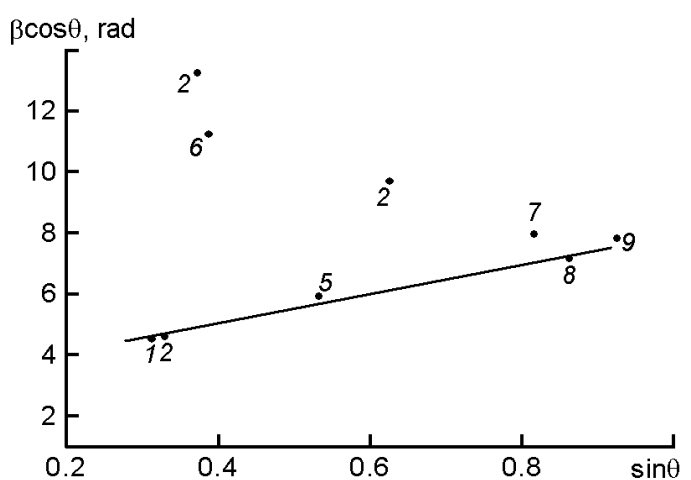

Fig. 1. The classic Hall's plot, graphed using a number of reflections from the quasicrystalline phase of $\mathrm{Ti}_{41.5} \mathrm{Zr}_{41.5} \mathrm{Ni}_{17}$, for the rapidly quenched ribbon sample: $1-(18,29)$, $2-(20,32), 3-(26,41), 4-(28,44), 5-$ $(52,84), 6-(72,116), 7-(122,197), 8-$ $(136,220), 9-(156,252)$. The indexes of reflections are given according to the method of J.Cahn [26].

the standard for the exclusion of geometric broadening is specially made from the same material. Obtaining of such quasi-standard is almost impossible. In our research, we chose a method of approximation, because it allows using any standard (we used dispersed diamond powder), and the width at the diffraction angle of interest is calculated from the approximating curve.

To study quasicrystals substructure this method requires some modernization. This necessity is caused by the following circumstances. Fig. 1 shows the original classical Hall's graph built for one of the rapidly quenched ribbon of $\mathrm{Ti}_{41.5} \mathrm{Zr}_{41.5} \mathrm{Ni}_{17}$. It was assumed that according to Neumann's principle for the quasicrystals with the fifth order rotational symmetry an isotropy of elastic properties should be performed. Therefore, for study by the classical method [23] all the reflections were selected which had their intensity and contrast allowed to register them securely. However, as shown in Fig. 1 not all the reflections lay on a single straight line, but only those that have one of the diffraction vector components equal $\mathbf{Q}_{\perp}<0.2 \mathrm{~nm}^{-1}$. Reflections of $\mathbf{Q}_{\perp}>0.2 \mathrm{~nm}^{-1}$ get out of the linear subjection, they are significantly broadened, and the substantial deviation is so greater from the linear dependence as greater the value of $\mathbf{Q}_{\perp}$.

In the classical method of approximation similar emission points from the linear dependence were also observed previously [24], and they were associated with the presence of stacking faults in the samples, 
which create additional broadening to micro dispersion and micro deformation and also displace maxima. Moreover, reflections with well-defined indexes get out of the general broadening dependence. Similar diffraction effects are created with phason defects on the diffraction patterns of quasicrystals $[14,15]$. It is known that because of the phasons presence the value of broadening and reflection displacement effect is proportional to the modulus of vector $\mathbf{Q}_{\perp}[12,14,15]$, that is one of the components of the diffraction vector $\mathbf{Q}$. According to the theory of diffraction and crystallography of quasicrystals [25.26] vector $\mathbf{Q}$ is a six-dimensional vector. It is laid out on $\mathbf{Q}^{6 D}=\mathbf{Q}^{3 D}{ }_{\mathrm{II}}+\mathbf{Q}^{3 D} \mathrm{~A}^{\wedge}$ two three-dimensional vectors. One of them is $\mathbf{Q}_{\mathrm{II}}$ that is originally linked with a cross section of reciprocal space by reflections surface (in so-called physical or "parallel" space), and its modulus is $\left|\mathbf{Q}_{\mathrm{II}}{ }^{3 D}\right|=1 / d=2 \sin \theta / \lambda$, and the second vector $\mathbf{Q}_{\perp}$ is an additional and perpendicular to the first one in six-dimensional space. Its modulus is calculated from the reflection indexes and the six-dimensional quasi-lattice parameter [26]. It is obtained that the broadening of diffraction peaks is a function of $\mathbf{Q}_{\mathrm{II}}$ and $\mathbf{Q}_{\perp}$. Therefore, to learn the substructure it is necessary to analyze the dependence of the reflexes broadening of the both diffraction vector components. Thus, the procedure for determining the parameters of the substructure is proposed to carry out in two stages. During the first stage a modernized (three dimensional) Hall's plot is made and by the method of the least squares in a special program the type of plane equation is determined that approximates the dependence of physical broadening from $\mathbf{Q}_{\mathrm{II}}$ and $\mathbf{Q}_{\perp}$ values. During the second stage - the DCS value, the micro deformations value and phason defects density are calculated from the plane equation coefficients.

\section{Results and discussion}

A modified Hall's graph for the same $\mathrm{Ti}_{41.5} \mathrm{Zr}_{41.5} \mathrm{Ni}_{17}$ ribbon sample is shown in Fig. 2. It can be seen that for all reflections (see Fig. 1), the values of physical width in dimensions of reciprocal space according to $\mathbf{Q}_{\mathrm{II}}$ and $\mathbf{Q}_{\perp}$ acceptably fit in the space near a plane. The analysis showed that the observed spread of points is not associated with any selected crystallographic direction. More likely, the reason lies in the spread of the error analysis of the experimental profiles and approximation error of the experi-

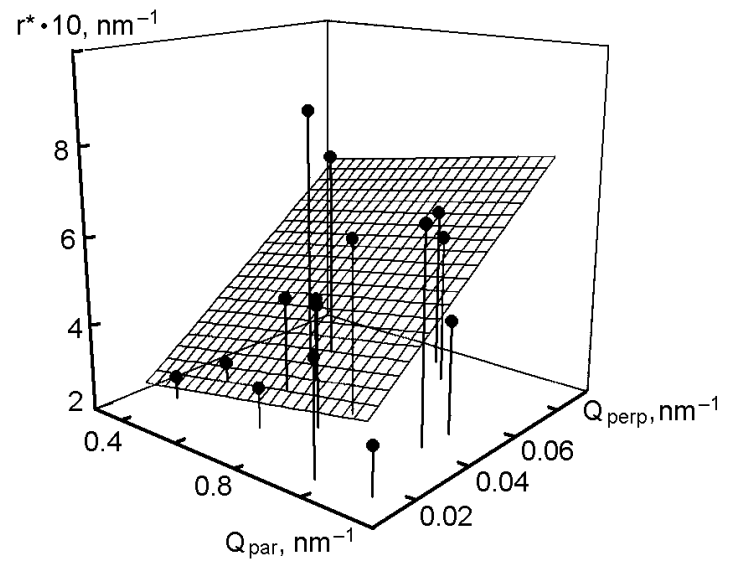

Fig. 2. Modified Hall's plot for samples $\mathrm{Ti}_{41.5} \mathrm{Zr}_{41.5} \mathrm{Ni}_{17}$ in the initial state.

mental profiles by Gauss and Cauchy functions. Approximating Gaussian function can artificially overrate the width of the narrow and intensive diffraction peaks, and Cauchy function may underestimate the width of the weak and broad peaks. As a result the diffraction maxima closely located at the corners that are differently affected by phasons may appear both above and below the approximating plane.

The expression for the value of the diffraction peak physical broadening, obtained as a result of the convolution of three Cauchy type functions, each of them describes one reason for the broadening: broadening caused by DCS $-\beta^{L}$, broadening caused by microdeformations $-\beta^{\varepsilon}$, and the broadening caused by phason defects $\beta^{f}$, will have the form

$$
\beta=\beta^{L}+\beta^{\varepsilon}+\beta^{f} .
$$

In the case of Gaussian approximation

$$
\beta^{2}=\left(\beta^{L}\right)^{2}+\left(\beta^{\varepsilon}\right)^{2}+\left(\beta^{f}\right)^{2} .
$$

In the dimension of reciprocal space, where $\beta^{L}=1 / L$, where $L-$ the average size of the domains of coherent scattering (DCS) along the diffraction vector $\mathbf{Q}_{\mathrm{II}}$ (coincides with the normal to the surface); $\beta^{\varepsilon}=2 \varepsilon \mathbf{Q}_{\mathrm{II}}$, $\varepsilon-$ the average micro deformations. Type expressions for $\beta^{f}$ were chosen so, what, M.A.Krivoglaz determines the dislocation dipoles [25]:

$$
\beta^{f} \approx b_{f} Q_{\perp} \sqrt{n_{f}},
$$

because in [7] phasons are identified with low dislocation dipoles. Here $b_{f}-$ the value of phason jump, $n_{f}-$ concentration 

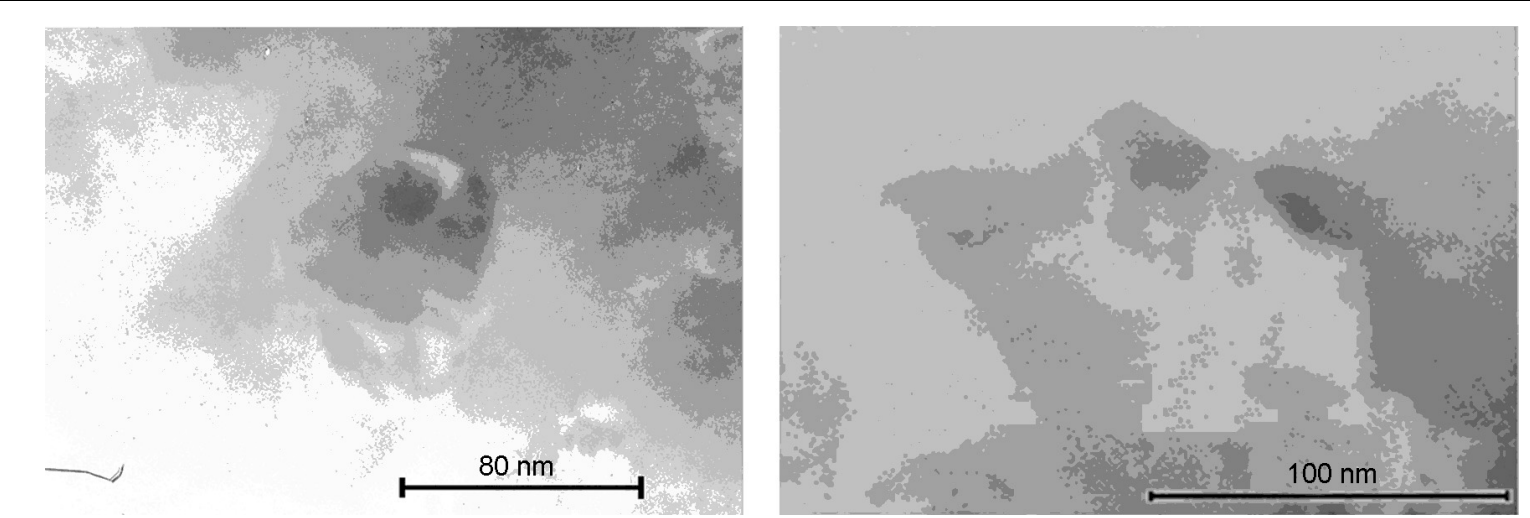

Fig. 3. Bright field electron-microscopic images of ribbon $\mathrm{Ti}_{41.5} \mathrm{Zr}_{41.5} \mathrm{Ni}_{17}$.

of phason defects. The value $b_{f} \approx 0.32 \mathrm{~nm}$, is calculated as the atomic displacement that occurs while rules violating of Penrose tiles, and this value was close to the experimentally found value for the $\mathrm{Al}-\mathrm{Cu}-\mathrm{Fe}$ quasicrystals [27]. Thus, the physical expansion of the diffraction peak is determined by the following expression:

$$
\beta=\frac{1}{L}+2 Q_{I I} \varepsilon+b_{f} Q_{\perp} \sqrt{n},
$$

which is the equation of this type of plane $Z=A+B x+C y$. The parameters of the substructure are calculated from the parameters of the equation.

Thus for the mentioned sample Gaussian approximation gives a value of DCS $L=71 \mathrm{~nm}$, a value of micro deformations $\varepsilon=0.7 \cdot 10^{-3}$, and the density of phason defects $n=2.87 \cdot 10^{12} \mathrm{~cm}^{-2}$. In the approximation of Cauchy $-L=120 \mathrm{~nm}, \varepsilon=1.2 \cdot 10^{-3}$, $n=6.7 \cdot 10^{11} \mathrm{~cm}^{-2}$, and it is known that the true values are in the middle. It may be noted that the data obtained in the first two parameters are quite reasonable. Our study using TEM, which results are shown in Fig. 3, also gives a value close to the size of DCS $100 \ldots 150 \mathrm{~nm}$. It's interesting, the order of phason density value is close to normal dislocation density for deformed crystals. Further checking of the method functionality is related to the fact that the structure and substructure state is determined by the composition and previous history of the sample. Fig. 4 shows that the intense fragmentation of ribbons led to a change in the nature of the approximating plane slope, which consists in increasing the intercept on $y$-axis, increasing an angle of the plane inclination relative to the axis of $\mathbf{Q}_{\text {II }}$ and weak change of the depending on $\mathbf{Q}_{\perp}$. Calculations show that the DCS value

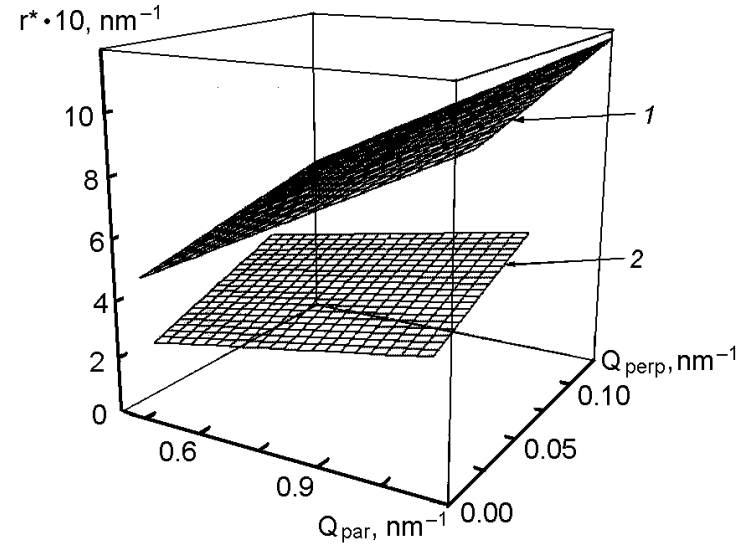

Fig. 4. Modified Halls' plots for sample $\mathrm{Ti}_{41.5} \mathrm{Zr}_{41.5} \mathrm{Ni}_{17}$ in the powder state (1) and in the ribbon state $(2)$.

decreased twice, micro deformations increased three times, and the density of phason defects decreased from $\approx 7 \cdot 10^{11}$ to $2 \cdot 10^{11} \mathrm{~cm}^{-2}$. Fig. 5 shows how different the nature of the approximating planes slope for three different quasicrystalline phases. For the icosahedral phase $\mathrm{Ti}_{41.5} \mathrm{Zr}_{41.5} \mathrm{Ni}_{17}$ there is a significant dependence of the slope from $\mathbf{Q}_{\text {II }}$ and $\mathbf{Q}_{\perp}$. For $\mathrm{Al}_{70} \mathrm{Pd}_{21} \mathrm{Re}_{9}$ phase dependence on $\mathbf{Q}_{\mathrm{II}}$ is the same, the dependence on $\mathbf{Q}_{\perp}$ is a little bit smaller, and the intercept on the ordinate axis is much smaller. For $\mathrm{Al}_{64.5} \mathrm{Pd}_{21} \mathrm{Mn}_{8.5}$ sample of the approximating plane slope is absent, it is almost parallel to the plane $O X Y$. The calculations of substructure are in the Table. It says that in sample $A I_{70} P d_{21} R e_{9}$ obtained from the equilibrium crystallization, there is the largest size of DCS and the lowest micro deformations. In the literature the phase $\mathrm{Al}_{64.5} \mathrm{Pd}_{21} \mathrm{Mn}_{14.5}$ is noted as one of the most perfect one $[3,11]$, indeed we note for this fast quenched sample the lowest density of phasons having quite small value of micro deformations. We also see that high- 

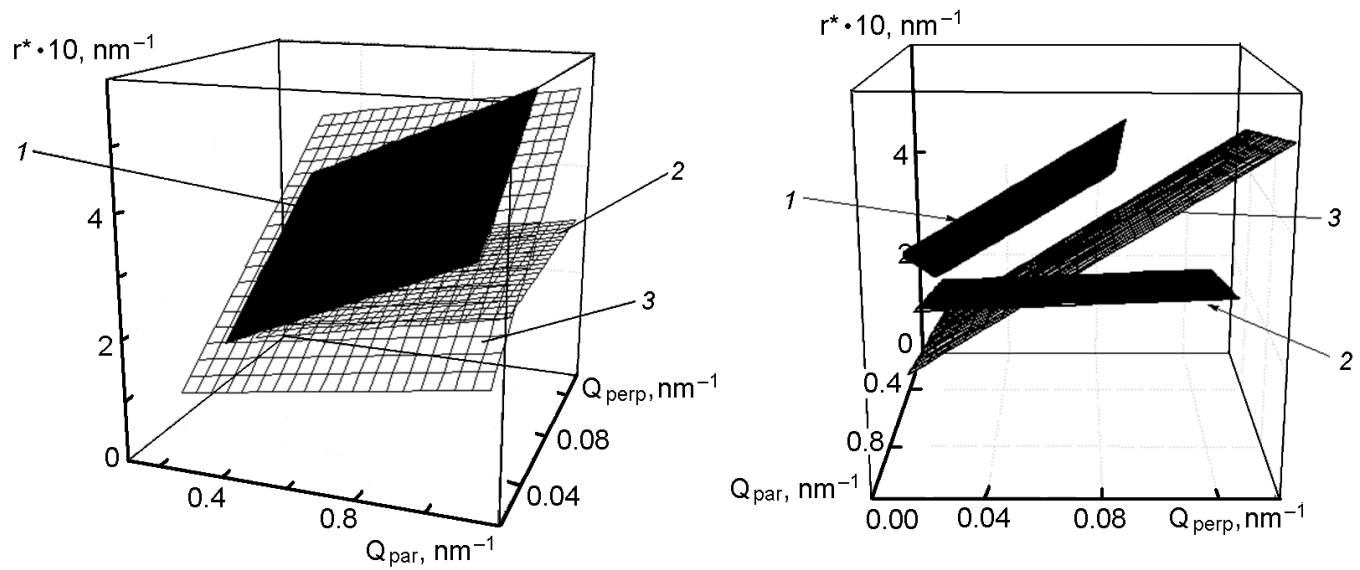

Fig. 5. Modified Halls' plots for samples $\mathrm{Ti}_{41.5} \mathrm{Zr}_{41.5} \mathrm{Ni}_{17}$ (1), $\mathrm{Al}_{64,5} \mathrm{Pd}_{21} \mathrm{Mn}_{8,5}$ (2) and $\mathrm{Al}_{70} \mathrm{Pd}_{21} \mathrm{Re}_{9}$ (3) in the initial state.

Table. The substructure parameters for the investigated samples

\begin{tabular}{|c|c|c|c||}
\hline \hline Sample & $L, \mathrm{~nm}$ & $\varepsilon$ & $n, \mathrm{~cm}^{-2}$ \\
\hline $\mathrm{Ti}_{41.5} \mathrm{Zr}_{41.5} \mathrm{Ni}_{17}$ ribbon & 120 & $1.2 \cdot 10^{-3}$ & $6,7 \cdot 10^{11}$ \\
$\mathrm{Ti}_{41.5} \mathrm{Zr}_{41.5} \mathrm{Ni}_{17}$ powder & 65 & $3.4 \cdot 10^{-3}$ & $2.3 \cdot 10^{11}$ \\
$\mathrm{Al}_{64.5} \mathrm{Pd}_{21} \mathrm{Mn}_{8.5}$ ribbon & 60 & $\mathbf{0 . 7} \cdot 10^{-3}$ & $3.5 \cdot 10^{9}$ \\
$\mathrm{Al}_{70} \mathrm{Pd}_{21} \mathrm{Re}_{9}$ massive & 170 & $0.42 \cdot 10^{-3}$ & $7.06 \cdot 10^{11}$ \\
\hline
\end{tabular}

speed quenching crushes DCS. Analyzing the data table, the following conclusion can be made. First, obtained substructure parameters using the developed technique are reasonable in order of value, and secondly, their modification while transition from one sample to another is consistent with the general ideas of the influence of thermo-mechanical treatment onto the structure of materials. Thus, we have for the first time the methodology of quantitative estimates of icosahedral quasicrystals substructure parameters by XRD.

The authors thank prof.H.R.Ott (Zurich, Switzerland) for providing the samples.

\section{Conclusions}

The method of the analysis substructure parameters of quasicrystalline objects by Xray diffraction was developed. The method was successfully worked out using quasicrystalline samples Al70Pd21Re9, Ti41,5Zr41,5Ni17 and Al64,5Pd21Mn14,5. The results are in good agreement with the prehistory of the samples.

\section{References}

1. D.Shechtman, I.Blech, D.Gratias, J.W.Cahn, Phys. Rev.Lett., 53, 1951 (1984).

2. Z.Stadnik, Physical Properties of Quasicrystals, Springer, Berlin (1999).

3. Yu.Kh.Vekilov, M.A.Chernikov, UFN., 53, 537 (2010).

4. C.Janot, Quasicrystals, Clarendon Press, Oxford (1994).

5. D. Gratia, $U F N, 156,2,48$ (1988) [In Russian].

6. C.Henley, M.de Boissieu, W.Steurer, Phil. Mag., 86, 1131 (2006).

7. M.Kleman, Eur. Phys. J. B: Condens. Matter Phys., 31, 315 (2003).

8. Sh. Kh. Hannanov, Fizika Metallov i Metallovedenie, 100, 5, 27 (2005).

9. M.de Boissieu, H.Takakura, M.Bletry, J. Alloys and Comp., 342, 265 (2002).

10. M.Feuerbacher, D.Caillard, Acta Materialia, 54, 3233 (2006).

11. T.Fujiwara, Yasushi Ishii, Quasicrystals, Handbook of Metal Physic, Elsevier, Amsterdam, Boston (2008).

12. M.Jono, Y.Matsuo, K.Yamamoto, Phil.Mag., 81, 2577 (2001).

13. M.Weller, M.Feuerbacher, J.Diehl, K.Urban, J.Phys., 6, 239 (1996).

14. V.Franz, M.Feuerbacher, M.Wollgarten, K.Urban, Phil. Mag. Lett., 79, 333 (1999).

15. A.Letoublon, F.Yakhou, F.Livet, Europhys. Lett., 54, 753 (2001).

16. M.Jono, Y.Matsuo, K.Yamamoto, Phil.Mag., 81, 2577 (2001).

17. M. A. Fradkin, Zh. Eksp. Teor. Fiz. Lett., 8, 395 (1992).

18. H.S.Chen, A.R.Kortan, J.M.Parsey, J.Phys. Rev., 38, 1654 (1988).

19. R.Nicula, A.Jianu, A.R.Biris, D.Lupu, Eur. Phys. J., 3, 1 (1998).

20. V.Azhazha, S.Borisova, S.Dub et al., Phys. Solid State, 47, 2262 (2005). 
21. V. M. Azhazha, S. V. Malykhin, B. A. Merisov et al., Probl. Atomic Sci. and Techn., Ser. Vacuum, Pure Mater., Supercond., 18 No.6, 115 (2009).

22. V.M. Azhazha, A.M. Bovda, S.D. Lavrinenko et al., Probl. Atomic Sci. and Techn., Ser. Vacuum, Pure Mater., Supercond., No.4, 82 (2007).

23. S. S. Gorelik, Yu. A. Skakov, L. N. Pastorguev, X-ray and Electron-optical Analysis, MISIS, Moscow (1994) [In Russian].
24. A. V. Kurdumov, Phase Changes in Carbon and Boron Nitride, Nauk. Dumka, Kiev (1979) [In Russian].

25. M. A. Krivoglaz, Diffraction of X-rays and Thermal Neutrons by Real Crystals, Nauk. Dumka, Kiev (1983) [In Russian].

26. J.Cahn, D.Shechtman, D.Gratias, J.Mat.Res., 1, 30 (1986).

27. G.Coddens, S.Lyonnard, B.Hennion, Y.Calvayrac, Phys. Rev., 62 (2000).

\section{Методика рентгенодифрактометричного дослідження субструктури ікосаедричних квазікристалів}

\section{С.В.Баздирєва, С.Н.Зубарєв, С.В.Малихін, А.Т.Пугачов, М.В.Решетняк, Н.В.Федчук}

3 використанням дослідних квазікристалічних зразків $\mathrm{Al}_{70} \mathrm{Pd}_{21} \mathrm{Re}_{9}, \mathrm{Ti}_{41,5} \mathrm{Zr}_{41,5} \mathrm{Ni}_{17} \mathrm{i}$ $\mathrm{Al}_{64,5} \mathrm{Pd}_{21} \mathrm{Mn}_{14,5}$ з різною технологією приготування розроблено і успішно відпрацьовано методику кількісної оцінки параметрів субструктури ікосаедричних квазікристалів, включаючи специфічні фазонні дефекти. В основу методу покладено аналіз ширини дифракційних ліній повної картини рентгенівської дифракції. Отримані результати знаходяться у добрій згоді з передісторією зразків. 